\title{
O ENSINO DE FILOSOFIA NO CONTEXTO DAS COMPETÊNCIAS E HABILIDADES DO NOVO ENSINO MÉDIO
}

\author{
THE TEACHING OF PHILOSOPHY IN THE CONTEXT OF THE SKILLS \\ AND HABILITIES OF THE NEW HIGH SCHOOL
}

\author{
Christian Lindberg Lopes do Nascimento \\ Professor doutor da Universidade Federal de Sergipe, São Cristóvão, SE, Brasil. \\ christianlindberg76@gmail.com - https://orcid.org/0000-0003-0325-5757
}

\author{
Nilmária Silveira Alves \\ Graduanda na Universidade Federal de Sergipe, São Cristóvão, SE, Brasil \\ niilsilveira729@gmail.com - https://orcid.org/0000-0002-9893-7007
}

Recebido em 28 de agosto de 2021

Aprovado em 26 de outubro de 2021

Publicado em 30 de dezembro de 2021

RESUMO: $O$ presente artigo tem o intuito de examinar como o ensino de Filosofia se insere no contexto das habilidades e competências. Para tanto, é crucial compreender os conceitos de habilidades e competências, com o objetivo de pensar de que maneira os conteúdos filosóficos podem ser preservados. Posto isso, a partir de um conjunto de leis responsáveis por fundamentar o que se entende por novo Ensino Médio, a instituição de uma Base Nacional Comum Curricular se tornou imprescindível. Tal documento normativo deve nortear a montagem do arranjo curricular de todas as escolas, públicas e privadas, de todo o Brasil, mobilizando os conhecimentos impreteríveis para os/as estudantes no decorrer do Ensino Médio. Entretanto, o/a leitor/leitora observará que a noção de competências e habilidades não é nova na literatura educacional brasileira como, de igual modo, alguns aspectos críticos acerca dos conceitos de habilidades e competências. A melhor compreensão do ensino de Filosofia no contexto do novo Ensino Médio tende a repercutir-se nas ações de resistência e, consequentemente, na manutenção de conteúdos filosóficos ao longo do processo de implementação da reforma. Devido ao fato de ser uma pesquisa com caráter qualitativo, o procedimento metodológico adotado foi a leitura estrutural de texto, combinada com a análise de conteúdo. As fontes consultadas foram livros, artigos científicos e a legislação educacional que, juntas, propiciaram a fundamentação do presente artigo.

Palavras-chave: BNCC. Competências. Ensino de Filosofia. Habilidades. Novo Ensino Médio.

ABSTRACT: This paper aims to examine how Philosophy Teaching fits into the context of skills and competences. So, it is essential to understand the concepts of skills and competences, in order to reflect how the philosophic contents have to be preserved. That said, from a set of laws responsible for grounding what is understood as a new High School, the institution of a Common National Curriculum Base became essential. Such normative document should guide the assembly of the 
curricular arrangement of all schools, public and private, throughout Brazil, mobilizing essential knowledge for students during High School. However, our reader will observe that the notion of skills and abilities is not a new one in Brazilian education literature, as well as some critical aspects about the concepts of abilities and competences. The best understanding of Philosophy Teaching in the New High School context, tends to tends to have repercussions on resistance actions and, consequently, on the maintenance of philosophical content throughout the process of implementing the Education reform. Since it is qualitative research, the methodological procedure the structural reading of the text was adopted, combined with content analysis. The consulted sources were books, scientific articles, and educational legislation that, together, provided the basis for this paper.

Keywords: CNCB. Competences. Philosophy Teaching. Abilities. New High School.

\section{Introdução}

O objetivo deste artigo é averiguar a condição do ensino de Filosofia no contexto das habilidades e competências. Parte-se da inquirição dos conceitos de competências e habilidades diante do contexto educacional brasileiro, mais especificamente do estatuto jurídico que normatizou as políticas públicas voltadas para o Ensino Médio ao longo das últimas décadas. Em seguida, a problematização é inserida nos termos contidos no novo Ensino Médio ${ }^{1}$, com ênfase ao Ensino de Filosofia, tentando elucidar limites e possibilidades práticas. Nesse interim, há o estabelecimento de um diálogo com objeções conceituais que os termos competências e habilidades despertaram.

Faz-se esse percurso conceitual por entender que o novo Ensino Médio alterou substancialmente a arquitetura curricular da última etapa da Educação Básica. Um dos mais controversos e polêmicos temas que pode ser observado é a adoção dos conceitos de habilidades e competências. De acordo com a Base Nacional Comum Curricular (BNCC) $)^{2}$, eles têm a função de mobilizar os conteúdos de aprendizagens necessários para os/as estudantes ao longo do Ensino Médio.

Os conceitos de habilidades e competências apareceram no debate educacional brasileiro no início dos anos 2000, especialmente nos documentos intitulado Parâmetros Curriculares Nacional para o Ensino Médio (PCN) e Orientações Educacionais Complementares aos Parâmetros Curriculares Nacionais $(\mathrm{PCN}+)$. Embora a Filosofia não fosse constituída como disciplina obrigatória na última etapa da Educação Básica, os dois documentos registraram orientações para o seu ensino nas escolas secundárias do País. No caso dos PCN, estabeleceu-se 
que, ao término do Ensino Médio, os/as estudantes fossem capazes de desenvolver as seguintes competências e habilidades (Quadro 1):

Quadro 1 - Competências e habilidades a serem desenvolvidas com os alunos do novo Ensino Médio

\begin{tabular}{|c|c|}
\hline COMPETÊNCIAS ESPECÍFICAS & HABILIDADES \\
\hline Representação e comunicação & $\begin{array}{l}\text { - Ler textos filosóficos de modo significativo; } \\
\text { - Ler, de modo filosófico, textos de diferentes estruturas e } \\
\text { registros; } \\
\text { - Elaborar por escrito o que foi apropriado de modo reflexivo; } \\
\text { - Debater, tomando uma posição, defendendo-a } \\
\text { argumentativamente e mudando de posição face a } \\
\text { argumentos mais consistentes; }\end{array}$ \\
\hline Investigação e compreensão & $\begin{array}{l}\text { - Articular conhecimentos filosóficos e diferentes conteúdos e } \\
\text { modos discursivos nas Ciências Naturais e Humanas, nas } \\
\text { Artes e em outras produções culturais. }\end{array}$ \\
\hline Contextualização sociocultural & $\begin{array}{l}\text { - Contextualizar conhecimentos filosóficos, tanto no plano de } \\
\text { sua origem específica, quanto em outros planos: o pessoal- } \\
\text { biográfico; o entorno sociopolítico, histórico e cultural; o } \\
\text { horizonte da sociedade científico-tecnológica. }\end{array}$ \\
\hline
\end{tabular}

Fonte: PCNs (2000)

No caso do $\mathrm{PCN}+$, a preocupação foi reforçar as competências específicas e habilidades inerentes ao Ensino de Filosofia já contidos nos PCN, com alguns acréscimos com caráter explicativo. Destaca-se, contudo, a importância de os conteúdos filosóficos serem ministrados com o intuito de dotar os/as estudantes de competências gerais de tal modo que ele/a possa fazer aprender. Como justificativa, alega as constantes transformações no mundo do trabalho como fator principal, tendo em vista a adaptação dos conteúdos filosóficos às demandas de cada contexto.

Mais do que transmitir conhecimentos, o professor deve promover competências gerais. Ou seja, mais do ensinar, deve "fazer aprender", uma vez que não se pode prever as modificações que virão a ocorrer em curto espaço de tempo nos mais diversos campos da cultura. O importante, no entanto, não consiste em menosprezar os conteúdos programáticos, e sim reconhecer que os conhecimentos são recursos a serem mobilizados nas mais inéditas e complexas situações reais. Caso contrário, de que adiantariam os saberes acumulados se não se transformassem em condições para serem aplicadas no trabalho, no convívio da família, no lazer, nas mais diversas situações que exijam reconfigurações dos conhecimentos e improvisação no agir? (BRASIL, 2002, p. 46). 
As Orientações Curriculares Nacionais (OCN), a exemplo do PCN+, destacam as habilidades e competências específicas para o ensino de Filosofia contidas nas PCN, além de acrescentar 30 (trinta) conteúdos de aprendizagem filosóficos necessários para mobilizá-las. A garantia da obrigatoriedade, primeiro pelo Conselho Nacional de Educação $(\mathrm{CNE})^{3}$ e depois pela sanção da Lei n. ${ }^{\circ}$ 11.684/2008, fortaleceu o caráter específico da Filosofia, mesmo mantendo as noções de habilidades e competências no processo de sua efetivação como disciplina obrigatória nos arranjos curriculares do Ensino Médio.

Se os conceitos de habilidades e competências são importantes para o novo Ensino Médio, parece ser relevante defini-los. Para Philippe Perrenoud (1999), competências seriam conhecimentos construídos e mobilizados a partir de uma rede de experiências, isto é, aquisições oriundas da mobilização de conhecimentos a partir de situações-problemas, por exemplo. Para ele, os seres humanos têm potencial para construir competências pelo aprendizado, desde que se adotem meios adequados. Entretanto, "[...] construir uma competência significa aprender a identificar e a encontrar os conhecimentos pertinentes", ou seja, é fazer com que o/a estudante aprenda a identificar, entre todo o conhecimento que possui, aquilo que for mais consistente. Assim, as competências permitem que o indivíduo tome decisões coerentes, resolva eficientemente conflitos com os quais se depara no cotidiano, além de desenvolver capacidades que mobilizam os conhecimentos adquiridos em prol da sua vida profissional e social.

Conforme o sociólogo, à medida que o/a estudante fizer o que precisa ser feito sem pensar, "[...] não se fala mais em competências, mas sim em habilidade" (PERRENOUD, 1999). Assim, as habilidades são a capacidade de aplicar certa competência a uma situação concreta, real. Elas são o saber fazer algo mediante formas eficazes e eficientes. As habilidades são desenvolvidas paralelamente com a aquisição das competências, ou seja, à medida que se constrói e mobiliza uma certa competência, desenvolve-se também determinada(s) habilidade(s).

Possuir habilidades significa estar em posse da capacidade de desenvolver as competências requeridas diante de uma ação, isto é, torna o indivíduo capaz de agir rápida e satisfatoriamente, de forma mecânica. Quanto mais mobilizada for uma 
competência, maior será a habilidade que o/a estudante terá na aplicação dessa tal competência e "[...] quanto mais especialista, menor o raciocínio e maior o apelo para conhecimentos pertinentes e funcionalmente estruturados" (PERRENOUD, 1999, p.08).

A construção e o aperfeiçoamento de competências e de habilidades, segundo Perrenoud, se dão na experiência. É impreterível recorrer à prática para que os conhecimentos sejam mobilizados; torna-se necessário criar situações em que, a partir dos conteúdos, desenvolvam competências e habilidades que permitam usar tais conhecimentos de maneira inteligente e eficiente. Com isso, o indivíduo deverá saber conhecer e fazer o que quer que seja em uma determinada situação, e isso denota a relação prática entre habilidades e competências. Perrenoud (1999) defende a importância de relacionar o conhecimento com a prática, haja vista que somente assim será possível construir competências, desenvolver habilidades e formar jovens capazes de lidar com as diversas situações do cotidiano. Nas palavras dele, "[...] é na possibilidade de relacionar, pertinentemente, os conhecimentos prévios e os problemas que se reconhece uma competência".

Também utilizada para fundamentar os conceitos de habilidades e competências, o documento intitulado Relatório para a UNESCO da Comissão Internacional sobre Educação para o século XXI pode auxiliar na compreensão dos dois termos. Coordenado por Jacques Delors, o relatório que ficou conhecido como Relatório Jacques Delors estabelece os quatro pilares fundamentais para a Educação no século XXI. A função da Educação é transmitir cada vez mais saberes e saber-fazer evolutivos que se adaptam à civilização cognitiva. Assim, cabe a ela oferecer as diretrizes de um mundo complexo e em constante transformação. Entretanto, pelo fato de a Humanidade viver em uma época marcada pela diversidade e pelo aprofundamento do conhecimento, cabe à Educação propiciar aos indivíduos "[...] aproveitar e explorar, do começo ao fim da vida, todas as ocasiões de atualizar, aprofundar e enriquecer estes primeiros conhecimentos, e de se adaptar a um mundo em mudança" (DELORS, 1999, p. 89). Em outros termos, é para servir a um mundo em constante mudança que a Educação, por intermédio da escola, deve formar as futuras gerações. 
Para tanto, a Educação deve se estruturar de modo a propiciar quatro aprendizagens fundamentais: 1) Aprender a conhecer, isto é, adquirir os instrumentos da compreensão; 2) Aprender a fazer, para poder agir sobre o meio envolvente; 3) Aprender a viver juntos, a fim de participar e cooperar com os outros em todas as atividades humanas; 4) Aprender a ser, via essencial que integra as três precedentes.

As transformações ocorridas no mundo do trabalho contribuíram para a redação do Relatório Jacques Delors. Afirma-se que o domínio dos aspectos cognitivo e informativo torna obsoleta a noção de qualificação profissional. Como contraponto, estabelece que a constituição de competências é mais apropriada para a dinâmica laboral do mundo contemporâneo. Profissões são criadas e extintas em uma velocidade atômica, empregos destinados aos seres humanos são substituídos por máquinas e as profissões procuram se adaptar a um oceano de inovações científicas e tecnológicas. Cada vez mais se sabe que elas se constituem em uma ferramenta adicional ao saber-fazer, o que exige de cada indivíduo o desenvolvimento de competências de comunicação, de trabalhar com o/a outro/a, de gerir e de resolver conflitos.

Diante do quadro conceitual, percebe-se que, ao destacar os conceitos de competências e habilidades, o novo Ensino Médio recorre não só a um vocabulário que pautou documentos governamentais do início do século XXI, mas também procura posicionar os/as estudantes secundaristas diante das exigências do atual cenário de transformações do mundo do trabalho e da vida social.

O impacto dos dois conceitos no campo educacional pode ser assim caracterizado. Grosso modo, define-se competências como um conjunto de aptidões, de capacidades que possibilitam ao indivíduo saber fazer, realizar determinadas tarefas, agir satisfatoriamente em uma dada situação. Para Ramos (2006, p.223) "[...] a noção de competência é frequentemente associada aos objetivos de ensino em pedagogia".

Quando o novo Ensino Médio é analisado, percebe-se que a BNCC apresenta como objetivo efetivar as 10 (dez) competências gerais da Educação Básica nos/as estudantes. São elas: 
As Competências Gerais da BNCC são: 1) Valorizar e utilizar os conhecimentos historicamente construídos sobre o mundo físico, social, cultural e digital para entender e explicar a realidade, continuar aprendendo e colaborar para a construção de uma sociedade justa, democrática e inclusiva; 2) Exercitar a curiosidade intelectual e recorrer à abordagem própria das ciências, incluindo a investigação, a reflexão, a análise crítica, a imaginação e a criatividade, para investigar causas, elaborar e testar hipóteses, formular, resolver problemas e criar soluções (inclusive tecnológicas) com base nos conhecimentos das diferentes áreas; 3) Valorizar e fruir as diversas manifestações artísticas e culturais, das locais às mundiais, e também participar de práticas diversificadas da produção artístico-cultural; 4) Utilizar diferentes linguagens - verbal (oral ou visualmotora, como Libras, e escrita), corporal, visual, sonora e digital -, bem como conhecimentos das linguagens artística, matemática e científica, para se expressar e partilhar informações, experiências, ideias e sentimentos em diferentes contextos e produzir sentidos que levem ao entendimento mútuo; 5) Compreender, utilizar e criar tecnologias digitais de informação e de comunicação de forma crítica, significativa, reflexiva e ética nas diversas práticas sociais (incluindo as escolares) para se comunicar, acessar e disseminar informações, produzir conhecimentos, resolver problemas e exercer protagonismo e autoria na vida pessoal e coletiva; 6) Valorizar a diversidade de saberes e vivências culturais e apropriar-se de conhecimentos e experiências que lhe possibilitem entender as relações próprias do mundo do trabalho e fazer escolhas alinhadas ao exercício da cidadania e ao seu projeto de vida, com liberdade, autonomia, consciência crítica e responsabilidade; 7) Argumentar com base em fatos, dados e informações confiáveis, para formular, negociar e defender ideias, pontos de vista e decisões comuns que respeitem e promovam os direitos humanos, a consciência socioambiental e o consumo responsável em âmbito local, regional e global, com posicionamento ético em relação ao cuidado de si mesmo, dos outros e do planeta; 8) Conhecer-se, apreciar-se e cuidar de sua saúde física e emocional, compreendendo-se na diversidade humana e reconhecendo suas emoções e as dos outros, com autocrítica e capacidade para lidar com elas; 9) Exercitar a empatia, o diálogo, a resolução de conflitos e a cooperação, fazendo-se respeitar e promovendo o respeito ao outro e aos direitos humanos, com acolhimento e valorização da diversidade de indivíduos e de grupos sociais, seus saberes, identidades, culturas e potencialidades, sem preconceitos de qualquer natureza; 10) Agir pessoal e coletivamente com autonomia, responsabilidade, flexibilidade, resiliência e determinação, tomando decisões com base em princípios éticos, democráticos, inclusivos, sustentáveis e solidários (BRASIL, BNCC).

Ao estabelecer um cruzamento de informações entre as destacadas pelo Relatório Jacques Delors e as competências gerais da BNCC, torna-se possível efetivar o seguinte quadro comparativo (Quadro 2). 
Quadro 2 - Comparação entre as competências do Relatório Jacques Delors e da BNCC

\begin{tabular}{|c|c|}
\hline Jacques Dellor's & 10 competências $=\mathrm{BNCC}$ \\
\hline $\begin{array}{l}\text { Aprender } \\
\text { conhecer }\end{array}$ & $\begin{array}{l}\text { 1. Valorizar e utilizar os conhecimentos historicamente construidos sobre } \\
\text { o mundo fisico, social e cultural para entender e explicar a realidade } \\
\text { (fatos, informaçðes, fenómenos e processos linguisticos, culturais, } \\
\text { sociais, económicos, cientificos, tecnológicos e naturais), colaborando } \\
\text { para a construção de uma sociedade solidária. } \\
3 \text {. Desenvolver o senso estético para reconhecer, valorizar e fruir as } \\
\text { diversas manifestaçóes artisticas e culturais, das locais às mundiais, e } \\
\text { também para participar de práticas diversificadas da produçăo artistico- } \\
\text { cultural. }\end{array}$ \\
\hline Aprender a fazer & 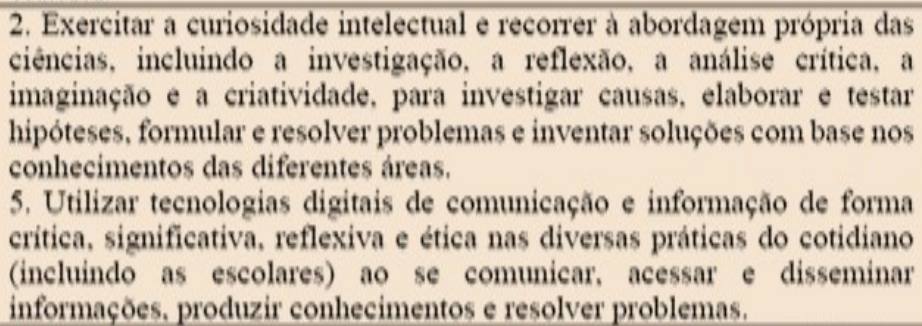 \\
\hline $\begin{array}{l}\text { Aprender a viver } \\
\text { juntos }\end{array}$ & $\begin{array}{l}\text { 4. Utilizar conhecimentos das linguagens verbal (oral e escrita) e/ou } \\
\text { verbo-visual (como Libras), corporal, multimodal, artistica, matemática, } \\
\text { cientifica, tecnológica e digital para expressar-se e partillar informaçôes. } \\
\text { experièncias, ideias e sentimentos em diferentes contextos e, com eles, } \\
\text { produzir sentidos que levem ao entendimento mútuo. } \\
9 \text {. Exercitar a empatia, o diálogo, a resoluçâo de conflitos e a cooperaçâo, } \\
\text { fazendo-se respeitar e promovendo o respeito ao outro, com acolhimento } \\
\text { e valorizaçâo da diversidade de individuos e de grupos sociais. seus } \\
\text { saberes. identidades. culturas e potencialidades, sem preconceitos de } \\
\text { origem. etnia. gênero. idade. habilidade/necessidade. conviçâo religiosa } \\
\text { ou de qualquer outra natureza. reconhecendo-se como parte de uma } \\
\text { coletividade com a qual deve se comprometer. }\end{array}$ \\
\hline Aprender a ser & 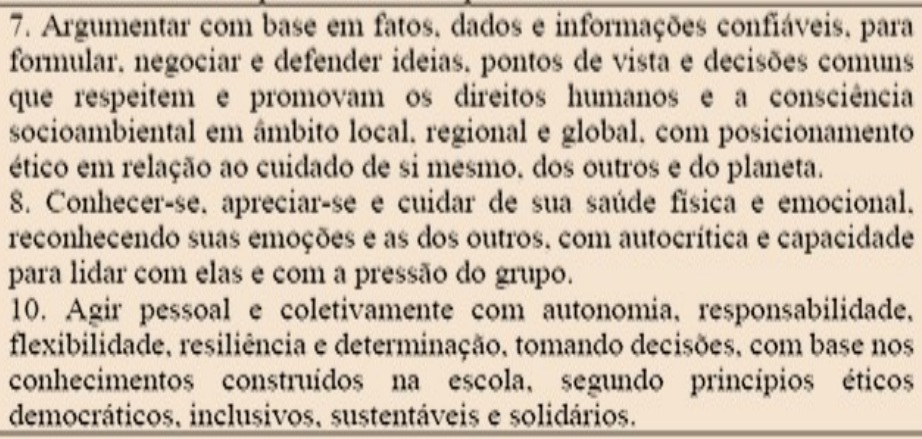 \\
\hline
\end{tabular}

Fonte: autores (2021)

No caso específico do Ensino Médio, percebe-se que, a partir da divisão do conhecimento em áreas, existe um conjunto de competências específicas e habilidades ${ }^{4}$ para cada uma delas (Quadro 3). 
Quadro 3 - Competências específicas e habilidades a serem desenvolvidas pelo aluno do Ensino Médio

\begin{tabular}{|l|c|c|}
\hline \multicolumn{1}{|c|}{ ÁREA DO CONHECIMENTO } & $\begin{array}{c}\text { COMPETÊNCIAS } \\
\text { ESPECÍFICAS }\end{array}$ & HABILIDADES \\
\hline Linguagem e suas tecnologias (LT) & 07 & 28 \\
\hline Matemática e suas tecnologias (MT) & 05 & 46 \\
\hline Ciências da Natureza e suas tecnologias (CNT) & 03 & 26 \\
\hline Ciências Humanas e Sociais Aplicadas (CHSA) & 06 & 32 \\
\hline
\end{tabular}

Fonte: autores (2021)

É bom ressaltar que a BNCC determina que a aprendizagem dos/as estudantes devem ser voltada para a assimilação, o desenvolvimento e o aperfeiçoamento das competências e habilidades. Assim, o arranjo curricular deverá criar situações, buscar meios didáticos que viabilizem a mobilização dos conteúdos de aprendizagem, dando preferência aos temas que possam ser contextualizados e aplicados no cotidiano de cada estudante.

Essa condição, no entanto, lança desafios para o ensino de Filosofia no âmbito da escola. Embora apareça de forma diluída e fragmentada, ele ganhou o status de estudos e de práticas no novo Ensino Médio, condição que, como se sabe, substituiu seu caráter disciplinar. Por mais que essa situação cause certa dúvida quanto a aplicabilidade em sala de aula, a noção de estudos e de práticas pode conferir à Filosofia certo espaço no arranjo curricular do novo Ensino Médio.

Os conteúdos da Filosofia devem ser trabalhados de maneira que contribuam, principalmente, para a formação ética e moral dos/as estudantes. Ele carece, por conseguinte, oferecer uma formação em que a aprendizagem permita ao/à estudante acessar os vários conhecimentos filosóficos de maneira significativa. Para tanto, é necessário selecionar conteúdos que possam ser úteis a essa formação, assim como criar e identificar situações-problema que possam ser aplicados em sala de aula e na vida. Por outro lado, os conteúdos filosóficos podem contribuir, também, com a formação dos/as estudantes para o mundo do trabalho e propiciarlhes conteúdos específicos e necessários para sua inserção de modo crítico e autônomo. 
No entanto, ao fazer uma leitura mais atenta das competências específicas ${ }^{5}$ da área CHSA, percebe-se uma diminuição de temas filosóficos que podem ser mobilizados para a efetivação das habilidades e competências contidas na BNCC. Assuntos relacionados à Lógica e à Estética, por exemplo, não são contemplados nas 32 habilidades da área, nem nas 6 competências específicas. No caso dos temas Ética e Filosofia Política, Epistemologia e Metafísica, observa-se que eles aparecem como possibilidades de seleção de conteúdos filosóficos, muito embora não contemple os diversos aspectos existentes em cada um ao longo da História da Filosofia. Isso implica dizer que, do ponto de vista comparativo, a BNCC reduziu a possibilidade de mobilização de conteúdos filosóficos ${ }^{6}$.

Considerando a situação que o novo Ensino Médio impôs à Filosofia, parece ser possível explorar as possibilidades existentes no âmbito da BNCC, movimento que tenta preservar, por menor que possa parecer, a presença de conteúdos filosóficos no processo de formação dos/as estudantes secundaristas. A competência específica 1 de CHSA, por exemplo, busca desenvolver a capacidade analítica e crítica para lidar com questões de ordem política, social, econômica, cultural, a partir da habilidade de compreender algumas categorias, a saber, ética, crítica, sociedade etc. A Filosofia, por sua vez, contribui para o desenvolvimento dessa habilidade a partir do estudo de ética, da sua importância para a vida coletiva e para a fundamentação da cidade, considerando o objetivo da habilidade específica 2, que é compreender a organização e o funcionamento da sociedade. Isso vale para a mobilização das habilidades da competência específica 5 , que visa, dentre outras coisas, combater as diversas formas de preconceitos mediante a adoção de princípios éticos, democráticos, inclusivos e solidários.

Outrossim, é impreterível mapear quais são as habilidades e competências estritamente filosóficas no âmbito da BNCC, especificamente as contidas na área CHSA. E nas demais áreas do conhecimento, não seria interessante realizar movimento semelhante? Não seria possível articular a Filosofia com as habilidades e competências de Linguagens e suas tecnologias, por exemplo? Como o objetivo do ensino filosófico é o desenvolvimento de capacidades que propiciem, aos/às alunos/as, meios para lidar com questões e situações diversas, é relevante pensar 
na articulação das competências e habilidades filosóficas com as das demais áreas. Aspectos da Lógica podem contribuir para a constituição de uma argumentação ${ }^{7}$ fundamentada em aspectos racionais e científicos, construídas de tal modo que evidenciem o que será afirmado de forma sistemática. Além disso, conceitos da área de Estética podem ser mobilizados para concretizar aspectos da Educação corporal e sensorial da área de Linguagens, como pode ser visto na competência específica $5^{8}$

Vale ressaltar que não é somente com a área de LT que as competências e habilidades filosóficas podem se articular. A habilidade 3 da competência específica 3, da área CHSA, por exemplo, permite pensar em um diálogo interdisciplinar com os conteúdos da área de Ciências Naturais, especificamente aqueles voltados para o tema da sustentabilidade. Tal habilidade busca, além do debate,

[...] avaliar o papel da indústria cultural e das culturas de massa no estímulo ao consumismo, seus impactos econômicos e socioambientais, com vistas à percepção crítica das necessidades criadas pelo consumo e à adoção de hábitos sustentáveis (BRASIL, 2018a).

Com isso, a Filosofia pode suscitar a reflexão acerca da ética ambiental, tendo em vista a caracterização do que é consumo, sustentabilidade, consumo sustentável, produção industrial, meio ambiente, natureza, mercadoria etc.

As possibilidades de mobilizar conteúdos filosóficos para dialogar, de forma interdisciplinar, com as diversas áreas do conhecimento existentes no âmbito da BNCC podem não ser o caminho mais simples a ser percorrido, muito menos o desejável. Contudo, diante do cenário de enfraquecimento do ensino de Filosofia, tal postura pode viabilizar espaços de resistência no interior do novo Ensino Médio 9 .

A experiência internacional pode auxiliar no reposicionamento da Filosofia no contexto do novo Ensino Médio. Aires Almeida e António Paulo Costa salientam algumas competências filosóficas no texto Avaliação das aprendizagens em filosofia - $10 \% 11^{\circ}$ anos, entre as quais o desenvolvimento das competências que objetivam saber identificar argumentos ${ }^{10}$, avaliá-los e propor novos argumentos, a partir da criatividade; denotam a intenção de desenvolver as seguintes competências: argumentativa, comunicativa e discursiva-filosófica. Ambas exigem, por sua vez, 
uma articulação entre os conteúdos de Português e Redação, por exemplo, com os de Filosofia, que culmina na noção de competências transversais.

\begin{abstract}
Uma competência transversal é um saber, um comportamento, uma atitude ou uma aptidão que não está vinculada a uma determinada disciplina escolar ou a um determinado contexto de aprendizagem, antes sendo requerida em várias disciplinas, em vários momentos da aprendizagem e mesmo para além da vida escolar do aluno (ALMEIDA; COSTA, 2004, p. 19).
\end{abstract}

A partir dessa transversalidade, é possível construir competências que visem, por exemplo, à avaliação, à refutação ou à construção de argumentos, bem como interpretar, analisar e sintetizar textos, mediante instrumentos filosóficos e linguísticos. Uma das competências que deve ser construída a partir do ensino de Filosofia é voltada para a representação e comunicação, a fim de desenvolver habilidades que permitam uma leitura significativa de textos filosóficos, debate mediante argumentos consistentes etc. Para tanto, o desenvolvimento da leitura e da escrita se faz imprescindível, elucidando a necessidade e a importância de articular competências e habilidades filosóficas com as de outras áreas.

Além da BNCC, outra possibilidade é inserir conteúdos de Filosofia nos denominados itinerários formativos ${ }^{11}$, visto que eles devem contemplar parte da carga horária total do novo Ensino Médio. Deve-se pensar essa inserção de modo interdisciplinar, seja no âmbito da própria área do conhecimento - CHSA -, ou em constante diálogo com os demais itinerários. Pode-se, por exemplo, construir itinerários voltados para questões temáticas, abordando aspectos contidos nos Temas Contemporâneos Transversais ${ }^{12}$. De igual modo, com a adoção do Projeto de Vida no Ensino Médio, abre-se outra fronteira onde os conteúdos filosóficos podem ser inseridos. Outra alternativa é constituir itinerários formativos com caráter disciplinar a partir das ausências temáticas da Filosofia existentes na BNCC.

Porém, à medida que as políticas públicas voltadas para a Educação reforçam a noção de competências e habilidades, percebe-se um movimento crítico sendo germinado e desenvolvido. Saviani (2013, p.435), por exemplo, identificou que a denominada pedagogia das competências parte do "[...] entendimento de que a fonte do conhecimento não está na percepção, mas na ação". Para ele, o objetivo 
central dela é constituir, nos indivíduos, comportamentos flexíveis, permitindo-lhes adaptação às mudanças de acordo com a velocidade em que elas acontecem em um mundo onde a própria sobrevivência não está garantida.

Newton Duarte (2001), ao identificar certa relação entre os conceitos de competências e habilidades e o construtivismo, estabelece um paralelo com os enunciados de Jacques Delors e Phillipe Perrenoud por meio da denominada expressão "aprender a aprender". Para tanto, dimensiona quatro posicionamentos valorativos: 1) São mais desejáveis as aprendizagens que o indivíduo realiza por si mesmo, nas quais está ausente a transmissão, por outros indivíduos, de conhecimentos e experiências; 2) É mais importante o/a estudante desenvolver um método de aquisição, de elaboração, de descoberta, de construção de conhecimentos, do que aprender os conhecimentos que foram descobertos e elaborados por outras pessoas; 3) A atividade do/a estudante, para ser verdadeiramente educativa, deve ser impulsionada e dirigida pelos próprios interesses; 4) A Educação deve preparar os indivíduos para acompanharem a sociedade em acelerado processo de mudança. Para ele, esses quatro elementos norteadores procuram preparar os indivíduos para conhecer a realidade social sem, contudo, fazer a crítica e/ou construir ações voltadas para a transformação da sociedade.

\begin{abstract}
Quando educadores e psicólogos apresentam o "aprender a aprender" como síntese de uma Educação destinada a formar indivíduos criativos, é importante atentar para um detalhe fundamental: essa criatividade não deve ser confundida com busca de transformações radicais na realidade social, busca de superação radical da sociedade capitalista, mas sim criatividade em termos de capacidade de encontrar novas formas de ação que permitam melhor adaptação aos ditames da sociedade capitalista (DUARTE, 2008, p.12).
\end{abstract}

De igual modo, Marilena Chauí (2016) estabelece uma crítica à noção de competências. Tendo como ponto de partida o conceito de ideologia, analisa as relações de produção da sociedade contemporânea e afirma que ela é administrável, racionalmente hierarquizada e funciona por si mesma, independentemente da sociedade. É nesse contexto que aparece o discurso da 
competência. Segundo Chauí (2016, p. 57): “[...] O discurso competente, portanto, é aquele proferido pelo especialista, que ocupa uma posição ou um lugar determinado na hierarquia organizacional". Desse modo, pode-se inferir que competência educacional se relaciona com a capacidade de um indivíduo adquirir algo proferido pelo especialista diante de um contexto em que a sociedade é hierarquizada e racionalmente ideologizada de acordo com os interesses da classe dominante. Em outros termos, ao adquirir determinada competência, o/a estudante se aliena diante de uma estrutura social hierárquica e ideológica, a ponto de incorporar a racionalidade administrada, nos moldes de uma cadeia de produção, e centrada na lógica da burguesia.

\footnotetext{
A ideologia da competência, negação da competência real, garante a alguns o direito de dirigir, controlar, manipular e punir os demais, reduzidos a meros executantes de ordens cujo fim, sentido e origem permanecem secretos. Esse mito transforma a capacidade real do processo de conhecimento em álibi para mandar e desmandar. O mito da competência é incompatível com a democracia social, política, econômica e cultural (CHAUÍ, 2016, p.118).
}

Luiz Carlos de Freitas identifica como reformas educacionais em curso no país, aquelas que estão associadas a interesses empresariais e são alinhadas com o que tem sido denominado de "nova direita". Ele afirma que "[...] a questão, portanto, não tem apenas um lado econômico, como querem fazer parecer os empresários. É também ideológica, no sentido de dar garantias à defesa da apropriação privada e sua acumulação contínua" (FREITAS, 2018, p.23). Nessas condições, a Educação é vista como um serviço, sequestrada pela perspectiva empresarial de que o problema escolar é uma questão de gestão, o que fundamenta "[...] a padronização promovida pelas bases nacionais comum curriculares e pela ação do movimento Escola sem partido" (FREITAS, 2018, p.29).

Algo semelhante é destacado por Michel Apple (2005), quando identifica que há uma fração da nova classe média profissional que faz parte da estrutura do Estado que compactua, mesmo que indiretamente, com os fins desejados pelas políticas de mercantilização da Educação e neoconservadoras. Para Apple (2005, p.52), "[...] como especialista em eficiência, gerência, testagem e responsabilidade, 
eles fornecem as habilidades técnicas para aplicar as políticas de modernização conservadora". Nesses termos, segundo ele, há uma espécie de aliança entre Mercado e auditores/gestores do Estado, o que demanda compreender de que maneira funciona para poder resistir, tendo ciência de que as escolas de Ensino Médio são locais complexos do ponto de vista organizacional e financeiro.

A LDB é, pode-se dizer, dúbia em relação ao tema do currículo escolar. Se por um lado, ela estabelece uma referência curricular nacional e com validade para todos os estados da federação, por outro, designa para cada rede (federal, estadual, municipal e particular) criar referenciais próprios, de forma contextualizada, o que permite encaminhar a decisão final para cada unidade escolar.

O problema de fundo é o entendimento do que vem a ser a base nacional comum que no artigo $9^{\circ}$ inciso IV da LDB prevê a definição de conteúdos mínimos enquanto nos artigos $8^{\circ}, 12^{\circ}$ e $15^{\circ}$ sugere a flexibilidade dos currículos a partir de expressões como "liberdade de organização", "os estabelecimentos de ensino terão a incumbência de elaborar e executar sua proposta pedagógica" e "autonomia pedagógica (FAVERO; KAPCZYNSKI, 2015, p.41).

Por ser um país extremamente desigual, o novo Ensino Médio pode contribuir com o aumento da desigualdade regional, devido as condições materiais que cada rede de ensino ou escola possui. Pode-se ter, por exemplo, 27 referenciais curriculares estaduais distintos e, em última instância, escolar, visto que cada unidade da federação tem autonomia para constituir o próprio referencial curricular.

No caso específico da Filosofia, que perde o caráter disciplinar, o impacto se torna ainda maior, já que há a diluição de seu conteúdo nas áreas de conhecimento, fragmentando seu ensino. Nesse sentido, torna-se necessário refletir de que modo os conteúdos filosóficos podem ser ensinados e trabalhados em sala de aula diante do novo Ensino Médio.

Por fim, ao enfatizar o ensino dos conteúdos de aprendizagem através da constituição de habilidades e competências que preparam o/a estudante para lidar com as questões do seu cotidiano, é crucial pensar em maneiras pelas quais os currículos podem ser constituídos, nos âmbitos estadual e escolar, e de que forma 
os conteúdos filosóficos podem ser assegurados em sala de aula, seja através das áreas de conhecimento da BNCC ou dos itinerários formativos.

\section{Referências}

ALMEIDA, A; COSTA, A. Avaliação das aprendizagens em filosofia $-10 \% 11^{\circ}$ anos. Ministério da Educação de Portugal. Apoio científico da Sociedade Portuguesa de Filosofia. Centro para o Ensino da Filosofia, [s. n.], 2004.

APPLE, M.W. Para além da lógica do mercado: compreendendo e opondo-se ao neoliberalismo. Rio de Janeiro: Editora DP\&A, 2005.

BRASIL. Ministério da Educação. Base Nacional Comum Curricular do Ensino Médio. Brasília: Editora MEC, $2018 a$.

BRASIL. Ministério da Educação. Diretrizes Curriculares Nacional para o Ensino Médio e Educação Profissional. Brasília: MEC, 2018b.

BRASIL. Ministério da Educação. Guia de implantação do novo Ensino Médio Brasília: MEC, 2019.

BRASIL. Ministério da Educação. Orientações curriculares para o Ensino Médio. v.3. Brasília: Editora MEC, 2006.

BRASIL. Ministério da Educação. Orientações educacionais complementares aos Parâmetros Curriculares Nacionais para o Ensino Médio: Ciências Humanas e suas tecnologias. Brasília: Editora MEC, 2002.

BRASIL. Ministério da Educação. Parâmetros Curriculares Nacionais para o Ensino Médio. Brasília, 2000.

BRASIL. Palácio do Planalto. Lei $\mathbf{n}^{0}$ 13.415. Conversão da Medida Provisória ${ }^{\circ}$ 746, de 2016. Altera as Leis ${ }^{\circ}{ }^{\circ}$ 9.394, de 20 de dezembro de 1996. Brasília, 2017.

CHAUÍ, M. A ideologia da competência. Belo Horizonte: Editora Autêntica, 2016.

DELORS, J. (org.). Relatório para a UNESCO da Comissão Internacional sobre Educação para o século XXI. São Paulo: Editora Cortez; MEC; UNESCO, 1998.

DUARTE, N. As pedagogias do "aprender a aprender" e algumas ilusões da assim chamada sociedade do conhecimento. Revista Brasileira de Educação, $n^{\circ} 18$, set/out/nov/dez, 2001. 
FAVERO, A. A.; KAPCZYNSKI, A. L. A filosofia na reforma curricular do Ensino Médio pós LDB: habilidades e competências na formação para a cidadania. Revista Digital de Ensino de Filosofia, v.2., n.2, jul./dez. Santa Maria, 2015. Disponível em: https://periodicos.ufsm.br/refilo/article/view/23827. Acesso em 05/03/2019.

FREITAS, L.C. A reforma empresarial da Educação: nova direita, velhas ideias. São Paulo: Editora Expressão popular, 2018.

PERRENOUD, P. Construir as competências desde a escola. Porto Alegre: Editora Artmed, 1999.

RAMOS, M. N. A noção de competências como ordenadora das relações educativas. In: A pedagogia das competências: autonomia ou adaptação. 3. ed. São Paulo: Editora Cortez, 2006. p. 221-281.

SAVIANI, D. História das ideais pedagógicas no Brasil. Campinas: Editora Autores Associados, 2013.

\section{Notas}

1 Entende-se por novo Ensino Médio o conjunto de leis que modificaram, de forma substantiva, aspectos conceituais, metodológicos, avaliativos, didáticos, estruturais e curriculares da última etapa da Educação Básica. Do ponto de vista legal, podem-se encontrar seus fundamentos na Lei $n$. $^{\circ}$ 13.415/2017, na Base Nacional Comum Curricular (BNCC), nas Diretrizes Curriculares Nacionais para o Ensino Médio e Educação Profissional (DCNEM) e no Plano Nacional do Livro Didático para o Ensino Médio (PNLD).

${ }^{2}$ A BNCC foi instituída para garantir, em âmbito nacional, uma formação geral básica para todos/as estudantes do Ensino Médio. Até a versão final, duas outras foram construídas e disponibilizadas para a sociedade debatê-las antes da versão final ser aprovada pelo Conselho Nacional de Educação e homologada pela presidência do País. O fato é que, entre a segunda e terceira versão da BNCC para o Ensino Médio, houve o golpe impetrado contra a então Presidenta Dilma Rousseff (PT), retirando-Ihe da presidência do Brasil. O Governo de Michel Temer (MDB), ao indicar Mendonça Filho (DEM) para ocupar o comando do MEC, modificou substancialmente o conteúdo das duas versões anteriores da BNCC, além de ter implementado uma alteração significativa no Ensino Médio brasileiro, que tem sido denominado de novo Ensino Médio.

${ }^{3}$ Parecer $n^{\circ} 38 / 2006 / C E B / C N E$.

4 A DCNEM, no art. $6^{\circ}$, define competência como sendo expressão dos direitos e objetos de aprendizagem, presentes na Lei $n .^{\circ} 13.005 / 2014$, que define o Plano Nacional de Educação, a serem desenvolvidos pelos estudantes. Por habilidade, a DCNEM é definida como unidades de competência que estão associadas ao saber fazer, ou seja, a capacidade, a proficiência ou a destreza para desempenhar tarefas, possibilitando a aplicação prática de conhecimentos. A BNCC/EM, em seu art. 3. ${ }^{\circ}$, define competência como a mobilização de conhecimentos (conceitos e habilidades), habilidades (práticas cognitivas e socioemocionais), atitudes e valores, para resolver demandas complexas da vida cotidiana, do pleno exercício da cidadania e mundo do trabalho. 
${ }^{5}$ As competências específicas da área de CHSA são: 1) Analisar processos políticos, econômicos, sociais, ambientais e culturais nos âmbitos local, regional, nacional e mundial em diferentes tempos, a partir da pluralidade de procedimentos epistemológicos, científicos e tecnológicos, de modo a compreender e posicionar-se criticamente em relação a eles, considerando diferentes pontos de vista e tomando decisões baseadas em argumentos e fontes de natureza científica; 2) Analisar a formação de territórios e fronteiras em diferentes tempos e espaços, mediante a compreensão das relações de poder que determinam as territorialidades e o papel geopolítico dos Estados-nações; 3) Analisar e avaliar criticamente as relações de diferentes grupos, povos e sociedades com a natureza (produção, distribuição e consumo) e seus impactos econômicos e socioambientais, com vistas à proposição de alternativas que respeitem e promovam a consciência, a ética socioambiental e o consumo responsável em âmbito local, regional, nacional e global; 4) Analisar as relações de produção, capital e trabalho em diferentes territórios, contextos e culturas, discutindo o papel dessas relações na construção, consolidação e transformação das sociedades; 5) Identificar e combater as diversas formas de injustiça, preconceito e violência, adotando princípios éticos, democráticos, inclusivos e solidários, e respeitando os Direitos Humanos; 6) Participar do debate público de forma crítica, respeitando diferentes posições e fazendo escolhas alinhadas ao exercício da cidadania e ao seu projeto de vida, com liberdade, autonomia, consciência crítica e responsabilidade.

${ }^{6}$ É complicado estabelecer o que deve ser ensinado quando o assunto é Filosofia. Porém, pode-se ter algumas referências para balizar o esvaziamento que o novo Ensino Médio estabeleceu ao Ensino de Filosofia. Um dos parâmetros por ser a Diretriz Curricular Nacional para os cursos de graduação em Filosofia, nos termos contidos na resolução $n^{\circ}$ 492/2001/CNE. Ela estabelece os componentes curriculares que devem constar, obrigatoriamente, nos cursos de licenciatura em Filosofia. Além do Estágio Supervisionado obrigatório e dos componentes voltados para a formação pedagógica, espera-se que, ao concluir o curso, o/a egresso de Filosofia adquira conhecimentos específicos de História de Filosofia, Lógica, Epistemologia, Ética e Filosofia Política, Teoria do conhecimento, Filosofia geral (Metafísica). Dessa forma, há a expectativa que os/as futuros professores/as de Filosofia tenham condições para ministrar conteúdos filosóficos na educação básica. Com nova legislação, a sintonia ente as diretrizes para os cursos de formação docente em Filosofia e a legislação para a educação básica deixou de existir.

${ }^{7}$ Não custa lembrar que a competência geral 7 , da BNCC, preconiza a relevância da argumentação com base em fatos, dados e informações confiáveis, para formular, dialogar e defender ideias e pontos de vistas. No caso específico da área de Linguagens, nota-se que a competência específica 3 permite a adoção de conteúdos da Lógica para sua efetivação.

${ }^{8}$ Competência específica 5 da área LT: Compreender os processos de produção e negociação de sentidos nas práticas corporais, reconhecendo-as e vivenciando-as como formas de expressão de valores e identidades, em uma perspectiva democrática e de respeito à diversidade.

${ }^{9}$ É bom destacar que as DCNEM indicam que as ações voltadas para o ensino-aprendizagem devem ser desenvolvidas de forma que rompa com o trabalho isolado das disciplinas (Art. 11, §5). Entretanto, compreende-se que só se viabiliza o caráter inter/transdisciplinar de algum componente se ele mantiver sua especificidade, sua particularidade, grosso modo, preservar seu caráter disciplinar. Esta celeuma criada pelo novo Ensino Médio tem causado certa dúvida quando os currículos estaduais são aprovados. Manter ou não manter o caráter disciplinar da Filosofia?

${ }^{10}$ Percebe-se que o Projeto de Vida (PV) ganhou status disciplinar com a adoção do novo Ensino Médio por parte dos estados. O PV, geralmente, tem pautado questões relacionadas ao empreendedorismo e futuro profissional.

11 São cinco os itinerários formativos: 1) Linguagem e suas tecnologias; 2) Matemática e suas tecnologias; 3) Ciências da Natureza e suas tecnologias; 4) Ciências Humanas e Sociais Aplicadas;

5) Formação técnica e profissional. 
ISSN: $2448-0657$

periodicos.ufsm.br/refilo Universidade Federal de Santa Maria/UFSM Santa Maria, RS, Brasil

REVISTA DIGITAL DE ENSINO DE FILOSOFIA

DOI: http://dx.doi.org/10.5902/2448065767446

12 Os Temas Contemporâneos Transversais são: 1) Meio Ambiente; 2) Economia; 3) Saúde; 4) Cidadania e civismo; 5) Multiculturalismo; 6) Ciência e Tecnologia.

\section{(c) (1) (9)}

This work is licensed under a Creative Commons Attribution-NonCommercial 4.0 International (CC BY-NC 4.0) 